\title{
Relationship between body image, body dissatisfaction and weight status in Iranian adolescents
}

\author{
Monireh Hatami ${ }^{*}$, Mohd Nasir Mohd Taib ${ }^{2}$, Abolghassem Djazayery ${ }^{3}$, Mansooreh Sadat Mojani ${ }^{2}$ and Fariborz Hamidi Mejlej ${ }^{4}$ \\ *Correspondence: monirehhatami@ymail.com

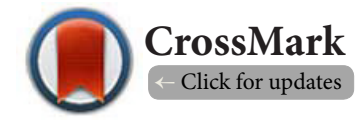 \\ 'Division of Prevention Development, Behzisti Organization, Ministry of Welfare and Social Security, Tehran, Iran. \\ ${ }^{2}$ Department of Nutrition and Health Sciences, Faculty of Medicine and Health Sciences, University Putra Malaysia Selangor, Malaysia. \\ ${ }^{3}$ Department of Nutrition and Biochemistry, School of Public Health, Tehran University of Medical Sciences, Tehran, Iran. \\ ${ }^{4}$ Mehrara Counselling Services Centre, Sattarkhan, Tehran, Iran.
}

\begin{abstract}
Background: In current society adolescents are concerned about body image. The relationship between body dissatisfaction and obesity is not clear in developing countries. This study sought to describe body image size perception and dissatisfaction, and their relationship with body weight status in adolescents.

Methods: Objective measures of weight and height were undertaken on 1109 schoolchildren aged 1018 (504 girls and 605 boys). BMI z-scores, and weight status were calculated based on the 2007 WHO growth reference charts. Figure rating scales were used to assess perceptions of current and ideal body size and dissatisfaction difference between these perceptions. Multivariate analyses were used to assess the relationship between the perceptions and dissatisfaction with body weight status.

Results: Perceived body image size was positively associated with weight status (partial regression coefficient for overweight/obese vs non-overweight/obese was 0.63 (95\% CI 0.26-0.99) and for BMI z-score was 0.21 (95\% CI 0.10-0.31), adjusted for sex and age). Body dissatisfaction was also associated with weight status, with overweight and obese children more likely to select thinner ideal body size than healthy weight children (adjusted partial regression coefficient for overweight/obese vs non-overweight/ obese was 1.47 (95\% CI 0.99-1.96) and for BMI z-score was 0.54 (95\% CI 0.40-0.67)).

Conclusions: Awareness of body image size and increasing body dissatisfaction with the higher weight status is established at a young age in this population. This needs to be considered when designing interventions to reduce obesity in young children, in terms of both benefits and harms.

Keywords: Body image, adolescents, obesity, body dissatisfaction, ideal body size

The increase in obesity prevalence has led the World Health Organization to refer to a 'global epidemic' to describe the obesity issue since 2000 [1]. Overweight and obesity are the emerging threats to the health status of adolescents living in developed countries as well as Asia and Pacific [2]. A particular concern about adolescence obesity refers to increasing obesity rates over the past 50 years, health consequences and consequent impact on adult obesity [3]. For better understanding risk factors of obesity in adolescents, obesity should be studied in different aspects such as social, psychological, biological, lifestyle or behavioural (including diet and activity). In adolescents, psychosocial factors including depression, anxiety, binge eating disorder, overeating,

body image perception and etc. predominantly are important and need to be understood and considered when designing prevention interventions. Among these factors, body image perception plays an important role in managing of body weight especially among adolescents. Body image discrepancy as a growing concept in societies influences on individuals' eating behaviour [4].

Definition of body image has changed over the past years. At first, body image was a picture of body formed by individuals in their mind [5]. Later, the definition of body image referred to some dimensions of the body in terms of aesthetics, size and shape [6]. Body image perception discrepancy refers to the discrepancy between perception of one's figure and the observable
\end{abstract}

\section{Introduction}


Hatami et al. Global Epidemic Obesity 2015,

real figure. As adolescence is the period of physical changes and transition from childhood to adulthood, adolescents become concerned with their size and weight.

According to the literature review conducted by Flynn and Fitzgibbon (1998) [7] body image can be a risk factor for obesity. A longitudinal study by Rosenblum and Lewis (1999) [8] among New Jersey adolescents indicated a positive relationship between body mass index and body dissatisfaction. Many studies have shown a link between body image especially body dissatisfaction and eating disorder [9-11], depression [12], body mass index [8]. Also, it was indicated that children negative body image due to excessive watching TV was correlated to obesity (when other variables were controlled) [13]. Even, some studies have shown that body image is more important than body mass index in obesity complications development. For example, the findings of a study by de Sousa (2008) [4] revealed that the proportion of adolescents who considered themselves obese was higher than the actual rate of obesity ( $12.7 \%$ vs $8.8 \%)$. Meanwhile, adolescents who were overweight/obese or persieve themselves overweight/obese frequently used more fitness strategies (such as going on diet, doing more exercise to change muscle size) [14].

Body image perception might be influenced by peers, parents, and the media [15-17] and also socioeconomic status, sex and body weight. Also overweight boys were more likely than overweight girls to perceive their body as about right. Higher percentages of adolescent girls and overweight boys from low socioeconomic status than those from middle/high SES perceived their body as too thin [18]. Moreover, body image perception can be related to the cultural aspects of a society $[18,19]$. For instance, Cinelli and O'Dea (2001) [20] indicated that indigenous adolescents in New South Wales were more likely to desire bigger bodies and weight gain. The cross-cultural influences on body image perception and behaviors of weight control were well illustrated by some researches who compared body image perception and weight control behaviors of adolescents across three communities in the USA, Lithuania and Croatia [21]. There were significant differences between the communities with regard to the perception of body image among adolescents. The researchers reported that sex and culture may affect on the adolescents' body image perception. Surprisingly, a published study in 2001, did not found any differences in body image concerns between Iranian and American women. It may be interesting to report and discuss about the influences (or lack of influences) of socio-cultural factors on obesity and body image concerns [22].

In developing countries, adolescents are also concerned with their body and body image discrepancy were exists. For example, in Malaysia, some researchers showed that body image perception may vary by body weight status among female adolescents [23]. They reported that a higher percentage of overweight adolescents had a more accurate perception than normal weight adolescents. However, body image discrepancy was greater in the overweight group than the normal group.

Body image perception might also be different in males and females. In females, the ideal body weight is thinner than their perceived size [24] which means that females wish to be slimmer. By contrast, a male's ideal body weight is bigger than their perceived size [25]. In Iran, limited studies found that adolescents who perceived themselves as an obese individual may eat less amounts of carbohydrate than those who perceived themselves as normal weight [26]. Meanwhile, girls may be more concerned about their appearance [27]. According to the literature, there is a lack of data to show the relationship between body image perception, body dissatisfaction and body weight status among Iranian adolescents. Therefore, this research hopes to add this association to the literature.

\section{Methods Participants}

To obtain an enough sample size, the highest available prevalence of overweight/obesity $(28.9 \%)\left(\mathrm{BMI} \geq 85^{\text {th }}\right.$ percentile) reported in a study conducted in Iran [28] among adolescents was applied in the following sample size formula [29]:

$$
\mathrm{n}=\frac{z_{1-\alpha / 2}^{2} \sum_{h=1}^{l} N_{h}^{2} P_{h}\left(1-P_{h}\right) / w_{h}}{N^{2} d^{2}}
$$

Where:

$\mathrm{n}=$ sample size

$\mathrm{N}=$ population of individuals in all strata (899000 students)

$\mathrm{z}_{1-\alpha / 2}=\mathrm{z}$ statistic for a level of confidence of $95 \%$ (1.96)

$\mathrm{d}=$ determining precision $(0.03)$

$\mathrm{N}_{\mathrm{h}}$ =population of individuals in stratum $\mathrm{h}$

$l=$ numbers of strata (in this study is 5)

$\mathrm{P}_{\mathrm{h}}=$ the prevalence of overweight and obesity in stratum $\mathrm{h}(0.29)$ $\mathrm{w}_{\mathrm{h}}=$ the proportion of population in stratum $\mathrm{h}$ to $\mathrm{N}$

So, a total of 1157 male and female adolescents aged 10-18 years participated in this study. However, a total of 48 students refused to participate in the study or did not complete the questionnaire making the final sample 1109 students. The sample recruited from 30 different primary, middle and high schools in Tehran. Sampling procedure followed a multistage stratified sampling design with regards to the distribution of students in educational districts in Tehran. To obtain a representative sample, based on the information obtained from Ministry of Education, the educational districts were divided into five geographical zones (central, north, south, west, and east). One district was then picked randomly from each geographical zone (strata). In each selected educational district, two schools were randomly selected (one for girls and one for boys) in each educational level. Hence, six schools in each district were selected: girls' primary school, boys' primary school, girls' middle school, boys' middle school, girls' high school, and boys' high school. Students were included if they were Iranian, not less than 10 or more than 18 years old. Within each selected school, participants were systematically chosen using available list of students' names in the principal's office. Written consent form was obtained from participating adolescents and their parents. The mean age of participants was 13.02 years $(S D=2.19)$ and their mean BMI was $20.17 \mathrm{~kg} /$ 
Hatami et al. Global Epidemic Obesity 2015,

$\mathrm{m}^{2}(S D=3.55)$. According to the WHO definition, samples were categorized to two groups: early adolescents between 10-14 years old and late adolescence between 15-19 years old.

\section{Measurement of weight status}

All measurements were conducted based on the published training and practical measurement guides by the World Health Organization [30]. Trained researchers measured twice for both weight and height in private area. Regular calibration of the equipments before and during the study based on the WHO guidelines, training of the anthropometrists based on detailed anthropometrical protocols of measurement and the performance of periodic controls of the measurement technique quality were performed to minimize technical errors and allow anthropometrists to reach better accuracy. Also, doing double measurement of a sub-sample of the population under study helped us to find and correct some measure of imprecision.

Weight was measured in light clothes and no shoes to the nearest $0.1 \mathrm{~kg}$ by a portable digital Seca 762 scale (Vogel \& Halke, Hamburg, Germany). Height was measured while subjects were in standing position, not wearing shoes, hat, hair bows, combs, and with normal position of shoulder to the nearest $0.1 \mathrm{~cm}$ by a portable/wall mounted stadiometer with movable head piece. All duplicate measurements for weight and height were recorded in the first page of the questionnaire and an average of two values for each measurement was calculated. Body mass index (BMI) was calculated by the formula: weight $(\mathrm{kg}) / \mathrm{height}$ $\left(\mathrm{m}^{2}\right)$ and standard deviation scores (BMI z-scores) derived using the age and sex specific 2007 WHO percentiles reference data [31]. Adolescents were also categorized as underweight, healthy weight, overweight and obese, according to the 2007 WHO growth reference data. BMI z-scores comprising of severely thin $(<-3 S D)$, thin $(\geq-3 S D$ and $<-2 S D)$, normal weight $(\geq-2 S D$ and $<+1 \mathrm{SD})$, overweight $(\geq+1 \mathrm{SD}$ and $<+2 \mathrm{SD})$ and obese $(\geq+2 \mathrm{SD})$ specified for sex respectively. In this study, we had three groups: normal weight, overweight and obese adolescents.

\section{Measurement of body image}

A figure rating scale, developed by Stunkard, Sorenson, and Schulsinger (1983) [32] was used to assess body image. Gender specific drawing consisted of 9 schematic figures ranging from 1 (very underweight) to 9 (very overweight) (Figure 1). The results are presented as current and desired size perceptions and a discrepancy score which is interpreted as a measure of body image dissatisfaction (BID). Current body size score minus desired body size score was interpreted as BID score. Thus negative or positive score indicated the adolescent perceived him/herself as more overweight or thinner than current respectively, whilst a zero score indicated satisfaction of body size.

\section{Procedure of data collection}

Data for the present study was collected between the middle of November 2009 to the end of May 2010 by the researcher and the other five well trained assistances. The respondents com-

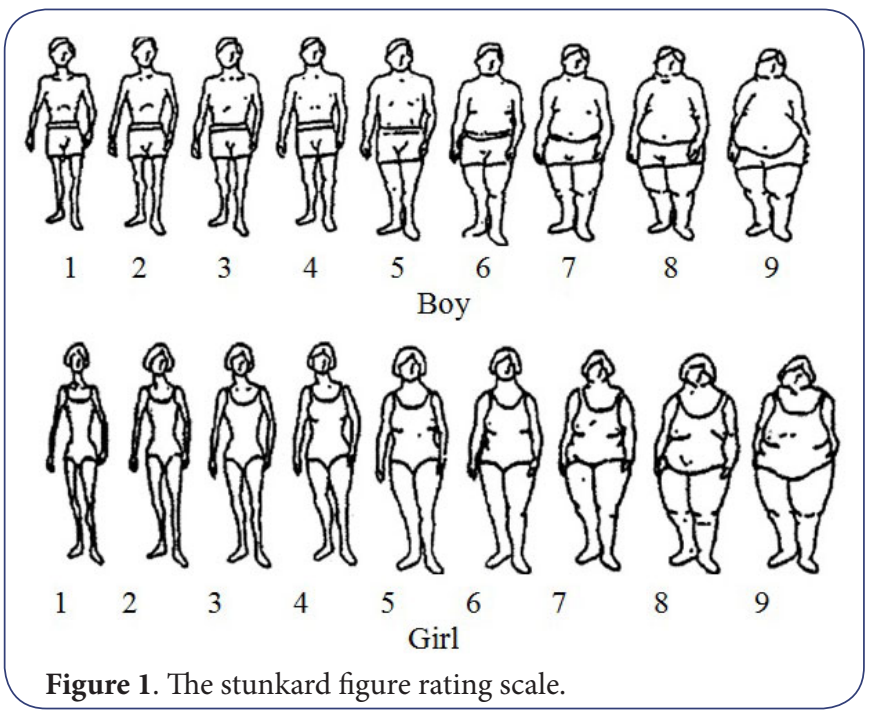

pleted the questionnaire during normal classroom hours. The aim of the study was explained for the respondents. They were reminded that the questionnaire was not a test, and that their information would remain anonymous and confidential. The respondents were encouraged to ask for help if they had problems in understanding the questions. They were requested to write their exact birth date instead of calculating their age to avoid probable miscalculations. The age of respondents was calculated by using the date of birth and date of completing the questionnaire (age=date of completing-date of birth). Most of the adolescents received some tips as incentives to manage their weight.

\section{Data analysis}

Analysis was undertaken using SPSS software (version 17) statistical package. The outcome variables explored were current body image perception, ideal body image perception, and body dissatisfaction scores. Chi-square tests were performed for bivariate categorical comparisons. Multiple regression analyses were performed for each outcome, with weight status, sex, and age as independent variables. Two alternative variables were used for weight status; BMI z-score and binary weight category (not overweight/obese versus overweight/obese).

\section{Results}

Data on age, gender, and weight status were obtained for 1140 adolescents, and 1109 of them completed the body image assessment (response rate $=97.28 \%$ ).

\section{Weight status}

The mean BMI z-score for the sample was $0.36(S D=1.02)$. One fifth of participants were either overweight or Obese (Table 1). There were no significant differences between the genders and the age groups.

\section{Perception of current body image (self)}

The mean self image score for the total sample was 3.97. The 
Hatami et al. Global Epidemic Obesity 2015,

distribution of current body image scores was similar across sexes (Table 2). The obese group had a higher median score for current body image than non-overweight/obese group (4.49 vs 3.84). Multiple regression models indicated that lower BMI z-score (or not being overweight/obese) was significantly associated with lower current body size perception scores (thinner self image) (Tables 3 and 4). Sex (being male) was not associated with perceived current body size scores. Subgroup analysis by sex found that the association between weight status and self perception image size was significant for both sexes. The mag-

Table 1. Weight study of study sample by sex and age.

\begin{tabular}{llll}
\hline & $\begin{array}{l}\text { Number (\%) } \\
\text { normal weight }\end{array}$ & $\begin{array}{l}\text { Number (\%) } \\
\text { overweight }\end{array}$ & $\begin{array}{l}\text { Number (\%) } \\
\text { obese }\end{array}$ \\
\hline Total & $879(79.3)$ & $160(14.4)$ & $70(6.3)$ \\
\hline Sex & & & \\
\hline Male & $402(79.8)$ & $70(13.9)$ & $32(6.3)$ \\
Female & $477(78.8)$ & $90(14.9)$ & $38(6.3)$ \\
\hline Age $^{\mathrm{b}}$ & & & \\
\hline $10-14$ & $612(78.9)$ & $121(15.6)$ & $43(5.5)$ \\
$15-18$ & $267(80.2)$ & $39(11.7)$ & $27(8.1)$ \\
\hline${ }^{\mathrm{a}} \chi^{2}=(1109,2)=0.22, \mathrm{p}=0.90 ;{ }^{\mathrm{b}} \chi^{2}=(1109,2)=4.91 ; \mathrm{p}=0.09$
\end{tabular}

nitudes of the associations were small.

\section{Perception of ideal body image}

The mean score for ideal body image was lower than that for current image size (mean=3.31). Distribution of scores is shown in (Table 2) and differed across sex groups with girls had a lower
Table 2. Distribution of current body image and ideal body image by sex.

\begin{tabular}{l|llll}
\hline $\begin{array}{l}\text { Figure rating } \\
\text { scale }\end{array}$ & $\begin{array}{l}\text { Number (\%) choosing } \\
\text { score for “ideal body } \\
\text { image" }\end{array}$ & $\begin{array}{l}\text { Number (\%) choosing } \\
\text { score for “current body } \\
\text { image" }\end{array}$ \\
\cline { 2 - 5 } & Girls & Boys & Girls & Boys \\
\hline 1 (Thinnest) & $53(8.8)$ & $10(2.0)$ & $12(2.0)$ & $9(1.8)$ \\
2 & $112(18.5)$ & $59(11.7)$ & $58(9.6)$ & $44(8.7)$ \\
3 & $243(40.2)$ & $179(35.5)$ & $162(26.8)$ & $126(25.0)$ \\
4 & $141(23.3)$ & $167(33.1)$ & $179(29.6)$ & $153(30.4)$ \\
5 & $52(8.6)$ & $63(12.5)$ & $133(22.0)$ & $116(23.0)$ \\
6 & $0(0)$ & $20(4.0)$ & $48(7.9)$ & $42(8.3)$ \\
7 & $2(0.3)$ & $6(1.2)$ & $9(1.5)$ & $10(2.0)$ \\
8 & $1(0.2)$ & $0(0)$ & $1(0.2)$ & $2(0.4)$ \\
9 (Fattest) & $1(0.2)$ & $0(0)$ & $3(0.5)$ & $2(0.4)$ \\
\hline
\end{tabular}

mean score than boys (3.08 vs 3.31 ). In contrast with the current body size perception scores, the ideal body size perception scores were similar across body weight status groups. Multiple regression models showed that adjusted for other factors, increasing age was significantly associated with lower ideal body size scores (thinner shapes) (Tables 3 and $\mathbf{4}$ ). Male sex was also significantly associated higher ideal self scores. Again, the magnitudes of the associations were small.

\section{Body dissatisfaction}

The mean body dissatisfaction score for the study sample was $0.66(S D=1.57)$. Mean scores for the different weight categories were $0.52(S D=1.49), 1.02(S D=1.68)$ and $1.61(S D=1.84)$ for

Table 3. Linear regression models to examine predictors for perceived current body image, perceived ideal body image, and body dissatisfaction scores.

\begin{tabular}{|c|c|c|c|}
\hline Variable & $\begin{array}{l}\text { Perceived current } \\
\text { image (Adjusted } R^{2}=0.09 ; \\
F=35.78 ; d f=3 ; p<0.001)\end{array}$ & $\begin{array}{l}\text { Perceived ideal image } \\
\text { (Adjusted } \mathrm{R}^{2}=0.05 ; \\
\mathrm{F}=22.19 ; \mathrm{df}=3 ; \mathrm{p}<0.001 \text { ) }\end{array}$ & $\begin{array}{l}\text { Body image discrepancy } \\
\text { (Adjusted } R^{2}=0.09 ; F=38.77 ; \\
d f=3 ; p<0.001 \text { ) }\end{array}$ \\
\hline & B $(95 \% \mathrm{CI})$ & B $(95 \% \mathrm{CI})$ & B $(95 \% \mathrm{CI})$ \\
\hline BMI z-score & $0.29^{* * *}(0.30-0.44)$ & $-0.03(-0.10-0.33)$ & $0.26^{* * *}(0.31-0.49)$ \\
\hline Age (year) & $0.06^{*}(0.002-0.004)$ & $-0.08^{* *}(-0.07--0.01)$ & $0.11^{* * *}(0.04-0.11)$ \\
\hline Male $^{\mathrm{T}}$ & $0.03(-0.08-0.22)$ & $0.23^{* * *}(0.39-0.65)$ & $-0.14^{* * *}(-0.63--0.27)$ \\
\hline
\end{tabular}

${ }^{\star} \mathrm{p}<0.05 ;{ }^{* *} \mathrm{p}<0.01 ;{ }^{* *} \mathrm{p}<0.001 ;{ }^{\mathrm{T}}$ Reference is: ${ }^{ }$Female

Table 4. Linear regression models for to examine perceived current and ideal body image and body dissatisfaction scores in relation to being overweight/obese vs not overweight/obese.

\begin{tabular}{|c|c|c|c|}
\hline Variable & $\begin{array}{l}\text { Perceived current image } \\
\text { (Adjusted } R^{2}=0.04 ; \\
F=17.65 ; \mathrm{df}=3 ; \mathrm{p}<0.001 \text { ) }\end{array}$ & $\begin{array}{l}\text { Perceived ideal image } \\
\text { (Adjusted } \mathrm{R}^{2}=0.05 ; \mathrm{F}=21.92 ; \\
\mathrm{df}=3 ; \mathrm{p}<0.001 \text { ) }\end{array}$ & $\begin{array}{l}\text { Body image discrepancy } \\
\text { (Adjusted } \mathrm{R}^{2}=0.08 ; \mathrm{F}=54.16 ; \\
\mathrm{df}=3 ; \mathrm{p}<0.001 \text { ) }\end{array}$ \\
\hline & B $(95 \% \mathrm{CI})$ & B $(95 \% \mathrm{CI})$ & B $(95 \% \mathrm{CI})$ \\
\hline Overweight/obese $\mathrm{e}^{\mathrm{t}}$ & $0.21^{* *}(0.47-0.84)$ & $-0.01(-0.19-0.13)$ & $0.18^{* *}(0.46-0.91)$ \\
\hline Age (years) & $0.05(-0.00-0.06)$ & $-0.08^{*}(-0.07-0.01)$ & $0.10^{*}(0.03-0.11)$ \\
\hline Male $^{\text {đT }}$ & $0.03(-0.07-0.23)$ & $0.23^{* *}(0.39-0.65)$ & $-0.14^{* *}(-0.63-0.23)$ \\
\hline
\end{tabular}

${ }^{\star} \mathrm{p}<0.01 ;{ }^{* \star} \mathrm{p}<0.001$; Reference is: ${ }^{\mathrm{T}}$ normal weight; Reference is: ${ }^{\mathrm{t}} \mathrm{Female}$ 
Hatami et al. Global Epidemic Obesity 2015,

normal weight, overweight and obese groups respectively. Only $24 \%$ were satisfied with their body size (BIDS score $=0$ ), $54.1 \%$ perceived themselves as thinner (BIDS score $<0$ ), and $21.6 \%$ as fatter than ideal body size (BIDS $>0$, Table 5 ). Mean scores across weight categories differed significantly $(F=21.43, p<0.001)$, with the overweight and obese categories having higher dissatisfaction scores than the normal weight category.

Multiple regression analyses indicated that adjusted for other factors, increasing body dissatisfaction score was associated with increasing BMI z-score (or overweight/obese) and increasing age. Also, being male was significantly associated with a lower BIDS (Tables 3 and 4). Additional analysis with considering males as reference group showed that being female was significantly associated with a higher BIDS.

\section{Discussion}

We found a high rate of body dissatisfaction (over 75\%) and a significant relationship between objectively measured weight status and body image perception and body dissatisfaction in Tehranian adolescents which confirm the limited previous studies conducted in Iran [33]. The findings across age subgroups indicate that even younger adolescents (at 10-14 age), have some self-awareness about their weight status and a concept of societal norms. The finding that current body image perception is associated with weight status in both sexes implies that male and female adolescents may be aware of their body shape at this stage, although boys appear to suffer lower levels of body dissatisfaction. Results showed that half of the adolescents perceived themselves thinner than their real weight which is in line with previous studies conducted among USA subjects [34]. Body image perception is thought of as a multidimensional phenomenon which involves external cultural and social as

Table 5. Body dissatisfaction by sex, age and weight status.

\begin{tabular}{llll}
\hline & $\begin{array}{l}\text { Number (\%) } \\
\text { perceived current } \\
\text { body image as } \\
\text { too thin } \\
\text { (BIDS }<\text { 0) }\end{array}$ & $\begin{array}{l}\text { Number } \\
\text { (\%) satisfied } \\
\text { (BIDS=0) }\end{array}$ & $\begin{array}{l}\text { Number (\%) } \\
\text { perceived } \\
\text { current body } \\
\text { image as too } \\
\text { fat (BIDS }>\text { 0) }\end{array}$ \\
\hline Total & $600(54.1)$ & $270(24.3)$ & $239(21.6)$ \\
\hline Sex & & & \\
\hline $\begin{array}{l}\text { Male } \\
\text { Female }\end{array}$ & $254(48.6)$ & $120(23.8)$ & $139(27.6)$ \\
\hline Age & $355(58.7)$ & $150(24.8)$ & $100(16.5)$ \\
\hline $\begin{array}{l}\text { 10-14 } \\
>14\end{array}$ & $405(52.2)$ & $184(23.7)$ & $187(24.1)$ \\
\hline Body weight status & & & \\
\hline $\begin{array}{l}\text { Non-overweight/ } \\
\text { obese }\end{array}$ & $438(49.8)$ & $240(27.3)$ & $201(22.9)$ \\
$\begin{array}{l}\text { Overweight/ } \\
\text { obese }\end{array}$ & $162(70.4)$ & $30(13.0)$ & $38(16.5)$ \\
\hline
\end{tabular}

${ }^{*} \chi^{2}=(1109,2)=20.84, \mathrm{p}<0.001$

${ }^{\mathrm{t}} \chi^{2}=(1109,2)=9.95, \mathrm{p}<0.01$

${ }^{\text {甲 }} \chi^{2}=(1109,2)=32.94, \mathrm{p}<0.001$ well as internal biological and psychological factors [6]. Many studies have been carried out to find the relationship between body image perception and body weight status in developed countries, but there is limited data on this issue in developing counties especially in the Middle-East region. Moreover, most of the studies focused on female adolescents presenting a difficulty in comparing between studies and the current study. The association between increasing weight status and body dissatisfaction found in this study has been little explored in Iran. Most of the conducted previous studies were among female adolescents; however; our findings based on a large, mixed sex sample suggest that body dissatisfaction with increasing weight status is established in both boys and girls. Our findings similar to the other studies show sex differences in body dissatisfaction $[35,36]$. Such differences are less pronounced in some populations. For example, a Malaysian study of body dissatisfaction in adolescents found a sex difference in Chinese, but not in Malay or Indian adolescents [37]. Weak but significant associations between male sex and higher scores for perceived ideal body size were found, indicating that on average, the perceived norms for body size are smaller for girls compared with boys. The sex difference in ideal body size perception is consistent with previous findings, indicating that boys generally desire larger body size and prefer

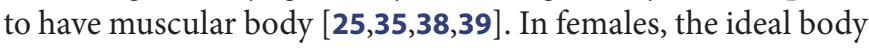
weight is thinner than their perceived size [24] which means that females wish to be slimmer. Several researchers reported that culture may also affect on the adolescents' body image perception. For example, the findings in Australia, Tonga and New Zealand $[\mathbf{2 0}, \mathbf{4 0}]$ indicated that having a big body and gaining weight are still counted as values by these societies confirming the role of culture on body image perception among adolescents. Before, the cross-cultural influences on body image perception and behaviors of weight control were well illustrated [21]; the researchers compared body image perception and weight control behaviors of adolescents across three communities in the USA, Lithuania and Croatia. There were significant differences between the communities with regard to the perception of body image among adolescents. They also reported that sex and culture may affect on the adolescents' body image perception. Moreover, body image perception can be related to the cultural aspects of a society $[\mathbf{1 8 , 1 9}]$. For instance, Cinelli and O'Dea (2009) [18] indicated that indigenous adolescents in New South Wales were more likely to desire bigger bodies and weight gain than their non-indigenous counterparts [27]. The researcher concluded that these findings would show the role of cultural attitudes in body image perception and in educational health programs.

The effect of social pressures, global mass media and religion on body image perception was shown in other studies $[\mathbf{7 , 1 7 , 4 1 ]}$. In developing countries, adolescents also are concerned with their body weight and body image dissatisfaction existence. For example, in Malaysia, it was reported that about $30 \%$ of overweight boys and $26.7 \%$ of overweight girls perceived themselves as normal weight [16]. In the other study, body image perception was found to vary by body weight status among Malaysian 
Hatami et al. Global Epidemic Obesity 2015,

female adolescents [23].

Given that the magnitudes of the associations were small in all regression analyses, it emphasized on this issue that BID is somewhat complex rather than unidirectional as presented in the current framework. It is a cross-cultural phenomenon, and also many other factors such as social (age, sex and educational level), familial (parental control), religious, acculturation level and media exposure, parenting style, birth weight and breast feeding are responsible for changes in BMI or the relationship between BID and body weight status which should be considered for future studies on body satisfaction $[19,41,42]$.

Although not the main focus of the study, an interesting finding is that a large proportion of adolescents (33\%) perceived themselves as too fat, the percentage of overweight/obese was $20.7 \%$. This qualities further exploration as this finding may also have implications in terms of obesity intervention. The findings of this study add to the existing body of knowledge on weight status and body image for a number of reasons. Firstly, this is a large study to explore the association in adolescents from both sexes. Secondly, this study attempted to understand the psychosocial functioning in Iranian adolescents in relation to obesity which seems crucial in developing interventions to reduce obesity in this group.

\section{Conclusions}

The findings of this study support the idea that adolescents have some awareness of their body size and of some societal norms, with more overweight children experiencing higher body dissatisfaction and a desire to be thinner. Areas for future research include an exploration of the longitudinal relationship between body image and dissatisfaction and future weight status in order to determine whether accuracy of weight perception or body dissatisfaction are potential predictors of weight change. These findings have potential implications for adolescence obesity intervention. If overweight and obesity lead to higher levels of body dissatisfaction in adolescents, as this study suggests, all components of intervention programmes aimed at reducing obesity in younger children should take this into account, and should be designed with sensitivity towards this issue. With this approach, interventions will minimise potential harm to children and will be beneficial, not only in terms of reducing obesity, but also by maximising their psychosocial health.

\section{Competing interests}

The authors declare that they have no competing interests.

\section{Authors' contributions}

Monireh Hatami: Design study, writing protocol, conducting study, data analysis and interpreting and revision of the paper.

Mohd nasir Mohd Taib: Design study, writing protocol, drafting of the article, data analysis.

Mansooreh sadat Mojani: Data analysis, revision of the paper.

Abolghassem Djazayery: Study design, drafting of the article and interpreting of results.

Fariborz Hamidi: Study design, data analysing, interpreting of results.

\section{Acknowledgment}

Authors would like to thank all students and their parents who participated in this study. Also, we are thankful the authorities of the Ministry of Education, Iran and all principals of the selected school for their co-operation to do this research.

\section{Publication history}

Samiran Bisai, Regional Medical Research Centre for Tribals (RMRCT), India.

Kurt Widhalm, Medical University of Vienna, Austria.

Received: 10 October 2014 Revised: 18 February 2015

Accepted: 26 March 2015 Published: 02 April 2015

\section{References}

1. WHO. Obesity, Preventing and managing the global epidemic, report of WHO consultation. Geneva: World health Organization, Technical Report series. 2000

2. Yoon JS and Lee NJ. Dietary patterns of obese high school girls: snack consumption and energy intake. Nutr Res Pract. 2010; 4:433-7. | Article | PubMed Abstract | PubMed FullText

3. Wang $\mathrm{Y}$ and Beydoun MA. Obesity Rates Continue to Climb in the United States. 2007.

4. de Sousa PM. Body-image and obesity in adolescence: a comparative study of social-demographic, psychological, and behavioral aspects. Span J Psychol. 2008; 11:551-63. | PubMed

5. Schilder PM. The image and appearance of the human body: studies in the constructive energies of the psyche New York. Great Britain: International Universities Press. 1999.

6. Cash T and Pruzinsky T. Body Image: A Handbook of Theory, Research, and Clinical Practice. New York: Guilford Press. 2004.

7. Flynn $\mathrm{KJ}$ and Fitzgibbon M. Body images and obesity risk among black females: a review of the literature. Ann Behav Med. 1998; 20:13-24. | Article | PubMed

8. Rosenblum GD and Lewis $\mathrm{M}$. The relation among body image, physically attractiveness, and body mass index in adolescence. Child Development. 1999; 70:50-64.

9. McCabe MP and Ricciardelli LA. Body image and strategies to lose weight and increase muscle among boys and girls. Health Psychol. 2003; 22:39-46. | Article | PubMed

10. Phares V, Steinberg AR and Thompson JK. Gender differences in peer and parental influences: Body image disturbance, self-worth, and psychological functioning in preadolescent children. Journal of Youth and Adolescence. 2004; 33:421-429| Article

11. Wiseman CV, Peltzman B, Halmi KA and Sunday SR. Risk factors for eating disorders: surprising similarities between middle school boys and girls. Eat Disord. 2004; 12:315-20. | Article | PubMed

12. Olivardia R, Pope Jr, Harrison G, Borowiecki III, John J and Cohane GH. Psychology of Men \& Masculinity. 2004; 5:112-120.

13. Fleming-Moran $\mathrm{M}$ and Thiagarajah K. Behavioral interventions and the role of television in the growing epidemic of adolescent obesity--data from the 2001 Youth Risk Behavioral Survey. Methods Inf Med. 2005; 44:303-9. I PubMed

14. Hatami M, Mohd Taib MN, Jamaluddin R, Abu Saad H and Djazayery A. Body change techniques in Iranian adolescents. Relationship to sex and body weight status. Appetite. 2013; 60:27-32. | Article | PubMed

15. McCabe MP, Ricciardelli LA and Finemore J. The role of puberty, media and popularity with peers on strategies to increase weight, decrease weight and increase muscle tone among adolescent boys and girls. $J$ Psychosom Res. 2002; 52:145-53. | Article | PubMed

16. Khor GL, Zalilah MS, Phan YY, Ang M, Maznah B and Norimah AK. Perceptions of body image among Malaysian male and female adolescents. Singapore Med J. 2009; 50:303-11. | Pdf | PubMed

17. Ricciardelli LA, McCabe MP and Banfield S. Body image and body change methods in adolescent boys. Role of parents, friends and the media. $J$ Psychosom Res. 2000; 49:189-97. | Article | PubMed 
Hatami et al. Global Epidemic Obesity 2015,

18. O'Dea JA and Caputi P. Association between socioeconomic status, weight, age and gender, and the body image and weight control practices of 6- to 19-year-old children and adolescents. Health Educ Res. 2001; 16:521-32. I PubMed

19. Ricciardelli LA, McCabe MP, Williams RJ and Thompson JK. The role of ethnicity and culture in body image and disordered eating among males. Clin Psychol Rev. 2007; 27:582-606. I Article I PubMed

20. Cinelli RL and O'Dea JA. Body image and obesity among Australian adolescents from indigenous and Anglo-European backgrounds: implications for health promotion and obesity prevention among Aboriginal youth. Health Educ Res. 2009; 24:1059-68. | Article | PubMed

21. Zaborskis A, Petronyte G, Sumskas L, Kuzman M and lannotti RJ. Body image and weight control among adolescents in Lithuania, Croatia, and the United States in the context of global obesity. Croat Med J. 2008; 49:233-42. | Article | PubMed Abstract | PubMed FullText

22. Abdollahi $P$ and Mann T. Eating disorder symptoms and body image concerns in Iran: comparisons between Iranian women in Iran and in America. Int J Eat Disord. 2001; 30:259-68. | Article I PubMed

23. Pon LW, Jr., Kandiah M and Mohd Nasir MT. Body image perception, dietary practices and physical activity of overweight and normal weight Malaysian female adolescents. Malays J Nutr. 2004; 10:131-47. | PubMed

24. Alipoor S, Goodarzi MA, Zarra-Nezhad M and Zaheri L. Analysis of the Relationship Between Physical Self-Concept and Body Image Dissatisfaction in Female Students. Journal of Social Sciences. 2009; 5: 60-66.

25. Kuan PX, Ho HL, Shuhaili MS, Siti AA and Gudum HR. Gender differences in body mass index, body weight perception and weight loss strategies among undergraduates in Universiti Malaysia Sarawak. Malays J Nutr. 2011; 17:67-75. I PubMed

26. Bidad K, Anari S, Tavasoli S, Nazemi L, Gholami N, Zadhush S and Moayeri $\mathrm{H}$. Dietary Intakes of Adolescent Girls in Relation to Weight Status. Iranian Journal of Public Health. 2008; 37:114-118. | Article

27. Espina A, OrtegoMA, de AldalO, AlemanAand Juaniz M. Body shape and eating disorders in a sample of students in the Basque country: a pilot study. Psychology in Spain. 2002; 6:3-11.

28. Mohammadpour-Ahranjani B, Rashidi A, Karandish M, Eshraghian MR and Kalantari N. Prevalence of overweight and obesity in adolescent Tehrani students, 2000-2001: an epidemic health problem. Public Health Nutr. 2004; 7:645-8. I Article I PubMed

29. Lemeshow S, Hosmer D.W, Klar J and Lwanga SK. Adequacy of sample size in health studies. New York, World Health Organization: Chichester [England] ; on behalf of the World Health Organization by Wiley. 1990.

30. WHO. WHO STEPS Surveillance, Part 3: Training and Practical Guides, Section 3: Guide to Physical Measurements (Step 2). 2009.

31. WHO . The WHO Child Growth Standards. 2007.

32. Stunkard AJ, Sorenson T and Schulsinger F. Use of the Danish Adoption Register for the study of obesity and thinness. In S. S. Kety, L. P. Rowland, R. L. Sidman, \& S. W. Matthysse, The Genetics of Neurological and Psychiatric Disorders. New York: Raven Press. 1983; 115-120.

33. Nobakht $M$ and Dezhkam M. An epidemiological study of eating disorders in Iran. Int J Eat Disord. 2000; 28:265-71. | Article I PubMed

34. Sarafrazi N, Hughes JP, Borrud L, Burt V and Paulose-Ram R. Perception of weight status in U.S. children and adolescents aged 8-15 years, 20052012. NCHS Data Brief. 2014; 1-7. | Pdf | PubMed

35. Ricciardelli LA and McCabe MP. Children's body image concerns and eating disturbance: a review of the literature. Clin Psychol Rev. 2001; 21:325-44. I Article I PubMed

36. Presnell K, Bearman SK and Stice E. Risk factors for body dissatisfaction in adolescent boys and girls: a prospective study. Int J Eat Disord. 2004; 36:389-401. | Article | PubMed

37. Mellor D, McCabe M, Ricciardelli L, Yeow J, Daliza N and Hapidzal NF. Sociocultural influences on body dissatisfaction and body change behaviors among Malaysian adolescents. Body Image. 2009; 6:121-8. | Article | PubMed
38. Ricciardelli LA, McCabe MP, Holt KE and Finemore J. A biopsychosocial model for understanding body image and body change strategies among children. Journal of Applied Developmental Psychology. 2003; 24:475-495.

39. Jones DC, Bain N and King S. Weight and muscularity concerns as longitudinal predictors of body image among early adolescent boys: a test of the dual pathways model. Body Image. 2008; 5:195-204. I Article I PubMed

40. McCabe MP, Fotu K, Mavoa H and Faeamani G. Body image and body change strategies among Tongan adolescents in Tonga and New Zealand. N Z Med J. 2010; 123:37-46. | PubMed

41. Kim KH. Religion, weight perception, and weight control behavior. Eat Behav. 2007; 8:121-31. | Article | PubMed

42. Sira N and Ballard SM. Gender Differences in Body Satisfaction: An Examination of Familial and Individual Level Variables. Family Science Review. 2011; 16:57-73.

\section{Citation:}

Hatami M, Taib MNM, Djazayery A, Mojani MS and Mejlej FH. Relationship between body image, body dissatisfaction and weight status in Iranian adolescents. Glob Epidemi Obes. 2015; 3:1.

http://dx.doi.org/10.7243/2052-5966-3-1 